\title{
ARTICLE Nimesulide increases the aldehyde oxidase activity of humans and rats
}

\author{
Lei Zhou ${ }^{1}$, Xiao-yan Pang ${ }^{1}$, Xiang-yu Hou ${ }^{1}$, Lu Liu' ${ }^{1}$, Zi-tao Guo ${ }^{1}$ and Xiao-yan Chen ${ }^{1}$
}

\begin{abstract}
An increasing number of drugs are metabolized by aldehyde oxidase (AOX), but AOX-mediated drug interactions are seldom reported due to the lack of appropriate inhibitors and inducers. A recent study reported that nimesulide (NIM) could increase the liver injury risk of methotrexate. The latter was mainly metabolized by AOX to form hepatotoxic 7-hydroxymethotrexate (7-OH MTX). Thus, we speculated that NIM could induce AOX. In this study, we investigated the potential induction of AOX activity by NIM using methotrexate as the probe substrate. Treatment of primary human and rat hepatocytes with NIM (20 $\mu \mathrm{M})$ for $24 \mathrm{~h}$ caused a 2.0- and 3.1-fold, respectively, increase in 7-OH MTX formation. Oral administration of NIM (100 mg $\cdot \mathrm{kg}^{-1} \cdot \mathrm{d}^{-1}$, for 5 days) to rats significantly increased the systematic exposure (6.5-fold), liver distribution (2.5-fold), and excretion (5.2-fold for urinary excretion and 2.1-fold for fecal excretion) of 7-OH MTX. The 7-OH MTX formation in liver cytosol from rats pretreated with 20, 50, and 100 $\mathrm{mg} \cdot \mathrm{kg}^{-1} \cdot \mathrm{d}^{-1}$ NIM for 5 days increased by 1.9-, 3.2-, and 3.7-fold, respectively, compared with that of rats pretreated with the vehicle. We revealed that the elevation of AOX activity was accompanied by an increase in AOX1 protein levels but not the corresponding mRNA levels. Collectively, our results demonstrate for the first time that NIM can increase the AOX activity of humans and rats, and may raise concerns regarding the risk of drug interactions between NIM and AOX substrates in clinical practice.
\end{abstract}

Keywords: nimesulide; aldehyde oxidase; induction; methotrexate; hepatocytes; pharmacokinetics; drug interaction

Acta Pharmacologica Sinica (2020) 41:843-851; https://doi.org/10.1038/s41401-019-0336-3

\section{INTRODUCTION}

Aldehyde oxidase (AOX) is a member of the molybdo-flavoprotein enzyme family that is mainly localized in the cytosolic subcellular fraction. It plays an important role in the oxidation of aromatic azaheterocycles. The common substrates for this reaction type include methotrexate (MTX) [1-3], SGX523 [4], JNJ-38877605 [5], and phthalazine [6-8] (Fig. 1). To date, the significance of AOX as a drug-metabolizing enzyme is increasing because of the trend in the medicinal chemistry strategy of introducing $\mathrm{N}$-heterocycle moieties, which can reduce or remove cytochrome P450 metabolic liability and achieve increased solubility and low lipophilicity, into candidate drugs. The proportion of potential AOX substrates among compounds that have already progressed to the drug market is $13 \%$, whereas that for compounds under development at Pfizer is $45 \%$ [9].

The number of drugs metabolized by AOX is increasing, but studies on AOX inhibition and induction are limited. AOX is induced by environmental pollutants and toxic agents, such as phthalazine [10], $N$-methyl- $N^{\prime}$-nitrosoguanidine [11], and dioxin $[12,13]$. To the best of our knowledge, no reports are available on AOX induction by commonly used clinical drugs.

MTX is an antifolate agent that is widely used in treating rheumatoid arthritis. Nimesulide (NIM) is a commonly prescribed nonsteroidal anti-inflammatory drug that can improve the therapeutic effect of MTX in the symptomatic alleviation of rheumatoid arthritis [14]. However, a recent study revealed that the combination of MTX with NIM increased the risk of liver injury
[15]. MTX was mainly metabolized by AOX to form 7hydroxymethotrexate (7-OH MTX), which displayed higher toxicity than the parent drug [16-18]. Thus, we speculated that NIM could increase the formation of the toxic metabolite 7-OH MTX by inducing AOX.

In the present study, we examined the effect of NIM on AOX activity in primary human and rat hepatocytes using MTX as a probe substrate. NIM was extensively metabolized in humans and rats. The main metabolic pathways included phenoxy ring hydroxylation to generate $4^{\prime}$-hydroxynimesulide (M1), reduction of the nitro group (M2), and subsequent acetylation (M4) (Fig. 2) [19]. The role of NIM metabolites in modulating AOX activity was also evaluated. Furthermore, we investigated the influence of NIM on the disposition of MTX and 7-OH MTX in rats and explored the changes in the protein and mRNA levels of AOX after NIM treatment.

\section{MATERIALS AND METHODS}

Chemicals and reagents

MTX, 7-OH MTX, and $d_{3}-M T X$ were purchased from Dalian Meilun Biotech Co. (Dalian, China). NIM, phthalazine, and protease inhibitor cocktail were obtained from Sigma-Aldrich (St. Louis, MO, USA). The 4'-hydroxynimesulide (M1), nitro-reduced nimesulide (M2), and acetylated metabolite of nitro-reduced nimesulide (M4) were synthesized as previously described [19]. SGX523 and JNJ-38877606 were purchased from Selleck Chemicals (Houston,

\footnotetext{
${ }^{1}$ Shanghai Institute of Materia Medica, Chinese Academy of Sciences, Shanghai 201203, China

Correspondence: Xiao-yan Chen (xychen@simm.ac.cn)
}

Received: 3 July 2019 Accepted: 18 November 2019

Published online: 8 January 2020 


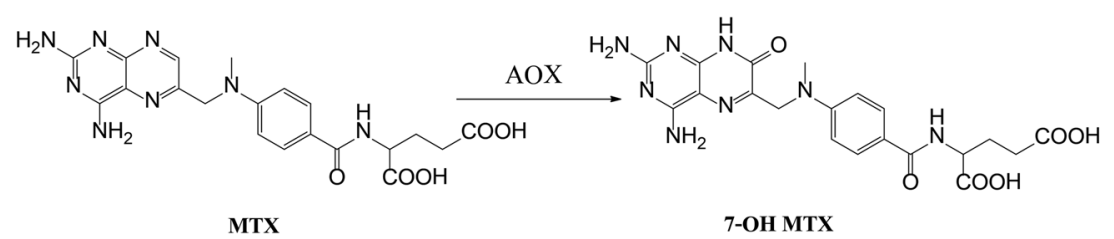

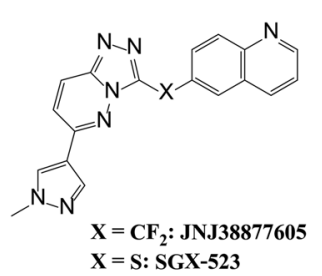

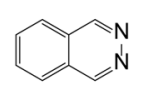

Phthalazine
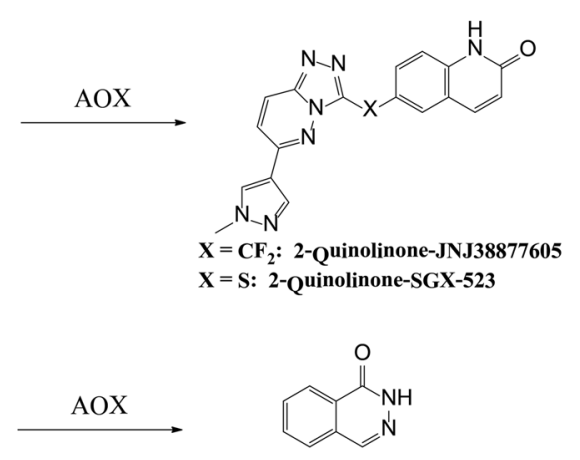

Phthalazone

Fig. 1 AOX-mediated oxidation of aromatic azaheterocyclic compounds.

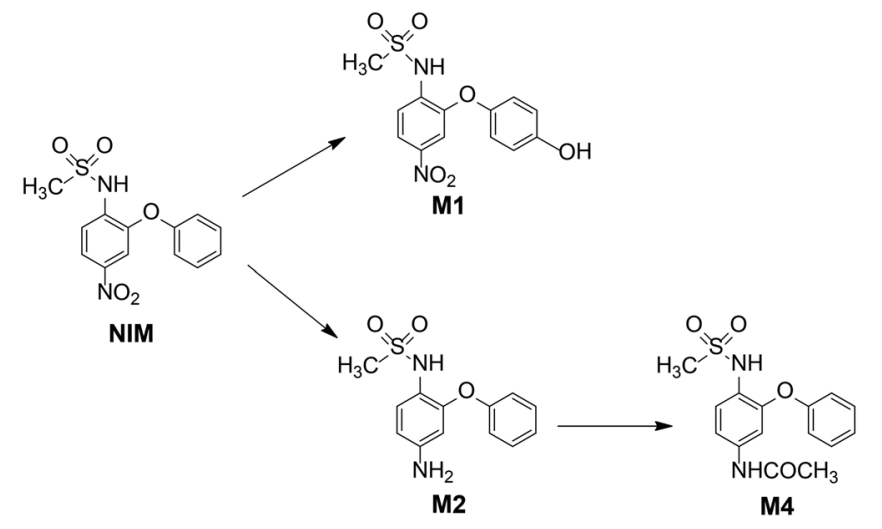

Fig. 2 Major metabolic pathways of NIM.

TX, USA). All reagents used in the cell culture were supplied by Invitrogen (Carlsbad, CA, USA). A bicinchoninic acid assay (BCA) protein assay kit and radioimmunoprecipitation assay (RIPA) buffer were purchased from Beyotime (Shanghai, China). The rabbit antiAOX1 polyclonal antibody and goat anti-AOX3 polyclonal antibody were obtained from Santa Cruz (Dallas, CA, USA). The rabbit anti-glyceraldehyde-3-phosphate dehydrogenase (GAPDH) monoclonal antibody was purchased from CST (Danvers, MA, USA). All other reagents and solvents were either of analytical or highperformance liquid chromatography grade.

Hepatocyte isolation and culture

Fresh rat hepatocytes were isolated from male Wistar rats (6-8 weeks) according to a previously reported method by our group $[19,20]$. Cryopreserved primary human hepatocytes from three individual donors (Lots: $\mathrm{RMH}, \mathrm{NHI}$, and DJj; Caucasian male) were obtained from BioreclamationIVT (Baltimore, MD, USA) and were revived according to the protocol. All hepatocytes were seeded at a density of $6.0 \times 10^{5}$ cells $/ \mathrm{mL}$ in 48 -well plates precoated with rat tail collagen and cultured in William's $E$ medium supplemented with $0.1 \mu \mathrm{M}$ dexamethasone, $100 \mathrm{U} / \mathrm{mL}$ penicillin, $100 \mu \mathrm{g} / \mathrm{mL}$ streptomycin, $2 \mathrm{mM}$ glutamine, and $1 \%$ insulin-transferrin-selenium. The hepatocytes were cultured for $4 \mathrm{~h}$ prior to the addition of the test compounds. All cell incubations were performed in triplicate and maintained at $37^{\circ} \mathrm{C}$ in a humidified incubator containing $95 \% \mathrm{O}_{2} / 5 \% \mathrm{CO}_{2}$.

To evaluate the effect of the induction time on the induction response, the rat hepatocytes were treated with either $0.1 \%$ dimethyl sulfoxide (DMSO) (control) or $20 \mu \mathrm{M}$ NIM for $12,24,48$, or $72 \mathrm{~h}$. At the end of the induction period, the hepatocytes were treated with MTX $(50 \mu \mathrm{M})$ for $24 \mathrm{~h}$ to determine the AOX activity. To evaluate the concentration-dependent induction of AOX by $\mathrm{NIM}$, the rat and human hepatocytes were treated with various concentrations of NIM (0-20 $\mu \mathrm{M}$ for rat hepatocytes and 0-100 $\mu \mathrm{M}$ for human hepatocytes) for $24 \mathrm{~h}$. At the end of the incubation, the hepatocytes were treated with MTX $(50 \mu \mathrm{M})$ to determine the AOX activity or harvested for Western blot and quantitative real-time polymerase chain reaction (qRT-PCR) analysis. To investigate whether the increase in AOX activity was due to NIM itself or its metabolites, rat and human hepatocytes were treated with the main metabolites (20 $\mu \mathrm{M}$ M1, M2, or M4) instead of NIM.

Animal experiments

All procedures in animal studies were performed in accordance with the Guide for the Care and Use of Laboratory Animals of Shanghai Institute of Materia Medica, Chinese Academy of Sciences.

Male Wistar rats weighing 200-250 g were randomized into two groups ( $n=4 /$ group) and treated with $100 \mathrm{mg} \cdot \mathrm{kg}^{-1} \cdot \mathrm{d}^{-1} \mathrm{NIM}$ or $0.5 \%$ sodium carboxymethyl cellulose (CMC-Na) as a control for 5 successive days. At $24 \mathrm{~h}$ after the last dose, all rats were orally administered $50 \mathrm{mg} / \mathrm{kg}$ MTX and reared in metabolic cages with one rat in each cage. Blood samples were collected before and at $0.25,0.5,1,2,4,6,8$, and $24 \mathrm{~h}$ after MTX administration. Plasma samples were obtained by centrifugation of blood samples at $11,000 \times g$ for $5 \mathrm{~min}$. Urine and fecal samples were collected during the $0-24 \mathrm{~h}$ period after MTX administration. In addition, two other groups of rats ( $n=4 /$ group) were treated with the same dosage regimen mentioned above. At $4 \mathrm{~h}$ after the MTX dosage, the rats were sacrificed, and rat livers were collected.

Two independent experiments were carried out to investigate the dose- and time-dependent induction of AOX in rat livers by NIM. First, male Wistar rats were randomized into four groups $(n=$ $5 /$ group) and orally administered 20,50 , and $100 \mathrm{mg} \cdot \mathrm{kg}^{-1} \cdot \mathrm{d}^{-1} \mathrm{NIM}$ or $0.5 \%$ CMC-Na as a control for 5 successive days. Second, male Wistar rats were randomized into six groups ( $n=5 /$ group) and 
Table 1. List of primers for qRT-PCR analysis.

\begin{tabular}{|c|c|c|c|c|}
\hline Species & Gene & Accession & & Sequence \\
\hline Rat & & & Reverse & 5'-ATTCGACTCGTAGCCCCTGA-3' \\
\hline Rat & & & Reverse & 5'-AGGCATCGAGGGAGATGATTC-3' \\
\hline Rat & GAPDH & NM_017008 & Forward & $5^{\prime}-$ CTCATGACCACAGTCCATGC - $3^{\prime}$ \\
\hline Human & & & Reverse & 5'-GGTGATGGGGTTGTATCGTGA-3' \\
\hline \multirow[t]{2}{*}{ Human } & PPIA & NM_021130 & Forward & 5'-CACCGTGTTCTTCGACATTG-3' \\
\hline & & & Reverse & 5'-TCCTTTCTCTCCAGTGCTCAG-3' \\
\hline
\end{tabular}

treated with $100 \mathrm{mg} \cdot \mathrm{kg}^{-1} \cdot \mathrm{d}^{-1}$ NIM or the vehicle for 1,3 , or 5 days. At $24 \mathrm{~h}$ after the last dose, the animals were anesthetized and sacrificed through exsanguination. The livers were collected for in vitro studies. All samples were frozen at $-80^{\circ} \mathrm{C}$ until further analysis.

\section{Rat liver cytosol (RLC) preparation and incubation}

The rat liver homogenate was prepared by resuspending the isolated liver tissue in homogenization buffer $(20 \% \mathrm{w} / \mathrm{v}$ in $0.25 \mathrm{M}$ aqueous sucrose solution containing $10 \mathrm{mM}$ Tris and $1 \mathrm{mM}$ disodium EDTA, $\mathrm{pH}$ 7.4) and then centrifuged at $10,000 \times g$ at $4{ }^{\circ} \mathrm{C}$ for $20 \mathrm{~min}$. The supernatant was further centrifuged at $100,000 \times g$ at $4^{\circ} \mathrm{C}$ for $60 \mathrm{~min}$. The resulting supernatant (cytosol) was collected and stored at $-80^{\circ} \mathrm{C}$ until use. The cytosol protein concentration was measured using a BCA protein assay kit.

The AOX activity in rat livers was determined by measuring AOX-mediated metabolites from probe substrates MTX [1, 21, 22], SGX523 [4], JNJ-38877605 [5], and phthalazine [6-8] in the RLCs prepared from different groups of rats. The incubation mixtures contained RLC $(1.0 \mathrm{mg} / \mathrm{mL})$, AOX substrates $(50 \mu \mathrm{M}$ MTX or phthalazine, $10 \mu \mathrm{M}$ SGX523 or JNJ-38877605), and PBS at a final volume of $100 \mu \mathrm{L}$. After $60 \mathrm{~min}$ of incubation at $37^{\circ} \mathrm{C}$ in a water bath, the reactions were terminated by adding an equal volume of ice-cold acetonitrile. To assess the involvement of AOX, the inhibitor menadione [4] $(10 \mu \mathrm{M})$ was added to the RLC incubation mixture. Each incubation was conducted in duplicate.

\section{Western blot analysis}

The hepatocyte samples were mixed with the sample loading buffer and boiled for $10 \mathrm{~min}$. Equal amounts of protein were subjected to electrophoresis on a $4 \%-20 \%$ Bis-Tris polyacrylamide gel (GeneScript, Nanjing, China) and transferred to a polyvinylidene difluoride membrane. PageRuler Prestained Protein Ladder (10-250 kDa) was used to define approximate molecular weights. The target protein was specifically bound to rabbit anti-AOX1 polyclonal antibody, goat anti-AOX3 polyclonal antibody, or rabbit anti-GAPDH monoclonal antibody. The signal was detected with a chemiluminescent agent (Millipore, Billerica, MA, USA) after incubation with anti-rabbit IgG conjugated with horseradish peroxidase (KPL, Gaithersburg, MD, USA) or anti-goat IgG conjugated with horseradish peroxidase (Beyotime, Shanghai, China).

Rat liver samples were homogenized in ice-cold RIPA buffer containing the protease inhibitor cocktail and then centrifuged at $11,000 \times g$ at $4{ }^{\circ} \mathrm{C}$ for $30 \mathrm{~min}$. The supernatant was evaluated for protein concentration using a BCA protein assay kit. The resulting liver samples were then treated in a manner similar to that of hepatocyte samples.
qRT-PCR analysis

RNA was extracted from hepatocyte or liver samples using TRIzol (Invitrogen, Carlsbad, CA, USA) and converted into cDNA by using the SuperScript III reverse Transcriptase Kit (Invitrogen, Carlsbad, CA, USA). qRT-PCR was performed on the Applied Biosystems $\mathrm{Vii}^{\mathrm{TM}} 7$ Real-Time PCR System (Carlsbad, CA, USA). The reaction was conducted in a $10-\mu \mathrm{L}$ solution containing $2 \mu \mathrm{L}$ of diluted cDNA, 250 or $500 \mathrm{nM}$ of each primer, and $5 \mu \mathrm{L}$ of SYBR Green PCR Master Mix (Applied Biosystems, Carlsbad, CA, USA) under the following conditions: $95^{\circ} \mathrm{C}$ for $10 \mathrm{~min}, 95^{\circ} \mathrm{C}$ for $15 \mathrm{~s}$, and $60^{\circ} \mathrm{C}$ for $60 \mathrm{~s}$ for 40 cycles. The primer sets are listed in Table 1. GAPDH was used as the internal standard gene for rat AOX1 and AOX3, and peptidylprolyl isomerase A (PPIA) was utilized for human AOX1. The cDNA levels were relatively quantitated by the comparative threshold cycle method described by Stiborova et al. [23].

Determination of AOX substrates and their metabolites

For measuring MTX and 7-OH MTX in rat plasma, urine, and in vitro incubation samples, $25 \mu \mathrm{L}$ of sample was mixed with $25 \mu \mathrm{L}$ of internal standard $\left(100 \mathrm{ng} / \mathrm{mL} \mathrm{d}_{3}-\right.$ MTX for plasma samples and 5 $\mu \mathrm{g} / \mathrm{mL}$ for urine and in vitro incubation samples) and $100 \mu \mathrm{L}$ of acetonitrile. After being vortexed and centrifuged at 11,000 $\times g$ for $5 \mathrm{~min}$, the supernatant was injected into the liquid chromatogram-tandem mass spectrometry (LC-MS/MS) system for analysis. Rat fecal and liver samples were homogenized in an acetonitrile/water $(1: 1, \mathrm{v} / \mathrm{v})$ solution and subsequently ultrasonicated for $20 \mathrm{~min}$. The resulting liver and fecal homogenates were treated in a manner similar to that described above. The $d_{3}-M T X$ concentrations for analyzing liver and fecal samples were $100 \mathrm{ng} /$ $\mathrm{mL}$ and $5 \mu \mathrm{g} / \mathrm{mL}$, respectively.

The LC system consisted of an LC-30AD pump equipped with a SIL-30AC autosampler (Shimadzu, Kyoto, Japan). MTX and 7-OH MTX were separated on an Eclipse Plus C18 $(100 \mathrm{~mm} \times 4.6 \mathrm{~mm}$ i.d., $3.5 \mu \mathrm{m}$; Agilent) column with gradient elution of $5 \mathrm{mM}$ ammonium acetate containing $1 \%$ formic acid (A) and acetonitrile (B) at $40^{\circ} \mathrm{C}$. The gradient conditions were as follows: $0-2.0 \mathrm{~min}, 10 \%-30 \% \mathrm{~B}$; 2.0-2.4 min, 30\% B; $2.4-3.0 \mathrm{~min}$, return to $10 \% \mathrm{~B}$; and $3.0-3.5 \mathrm{~min}$ re-equilibrium. The flow rate was $0.7 \mathrm{~mL} / \mathrm{min}$. MS detection was performed using an AB Sciex Triple Quad 5500 System (Applied Biosystems, Concord, ON, Canada) equipped with a TurbolonSpray ion source. Multiple reaction monitoring was used to quantify compounds in the positive ion mode $(\mathrm{m} / \mathrm{z} 455.2 \rightarrow \mathrm{m} / \mathrm{z} 308.2$ for MTX; $m / z \quad 471.2 \rightarrow m / z \quad 324.2$ for 7-OH MTX; and $m / z 458.2 \rightarrow m / z$ 311.2 for $\left.d_{3}-M T X\right)$. For assaying MTX and 7-OH MTX in plasma and liver samples, the standard curve ranged from 0.01 to $10 \mu \mathrm{g} / \mathrm{mL}$ for MTX and 0.1 to $100 \mathrm{ng} / \mathrm{mL}$ for 7-OH MTX. For assaying MTX and 7-OH MTX in urine, feces and in vitro incubation samples, the standard curve ranged from 0.1 to $100 \mu \mathrm{g} / \mathrm{mL}$ for MTX and 1 to 
$1000 \mathrm{ng} / \mathrm{mL}$ for $7-\mathrm{OH}$ MTX. The relative standard deviation (precision) and relative error (accuracy), calculated from quality control samples, were less than $15 \%$ for each analyte in the biological matrix.

SGX523, JNJ-38877605, phthalazine, and their AOX-mediated metabolites were detected using ultraperformance liquid chromatography/quadrupole time-of-flight mass chromatography as described previously [24].

Statistical analysis

Pharmacokinetic parameters, including the maximum plasma concentration $\left(C_{\max }\right)$, time to reach $C_{\max }\left(t_{\max }\right)$, elimination halflife $\left(t_{1 / 2}\right)$, area under the plasma concentration-time curve (AUC), and mean residence time (MRT), were calculated according to a noncompartmental model using Phoenix WinNonlin 6.4 (Pharsight, Mountain View, CA, USA) software. Data are expressed as the mean \pm standard deviation (SD) and illustrated using GraphPad Prism 5.0 software. All statistical comparisons were performed using the unpaired two-tailed Student's $t$-test. ${ }^{*} P<0.05$, ${ }^{* *} P<0.01$, and ${ }^{* *} P<0.001$ were considered statistically significant.

\section{RESULTS}

Increase in AOX activity in rat and human hepatocytes

AOX was the main enzyme that catalyzed 7-OH MTX formation from MTX [1, 21, 22]. Cytochrome P450s did not contribute to the metabolism of MTX [25]. Thus, MTX was used as the probe substrate to evaluate the AOX activity in our study. First, the effect of the induction time on the induction response was evaluated. The rat hepatocytes were treated with either vehicle control or NIM for $12,24,48$ or $72 \mathrm{~h}$. Afterward, MTX was added to determine the AOX activity. As displayed in Fig. 3a, the 7-OH MTX formation in the vehicle control-treated cells significantly decreased with the increase in the preincubation period from 12 to $72 \mathrm{~h}$, indicating a decrease in AOX activity. Compared with the control group, incubation with NIM for $12,24,48$, and $72 \mathrm{~h}$ increased the 7-OH MTX yield by 1.7-, 2.5-, 2.7-, and 2.7-fold, respectively (Fig. 3a).

According to the abovementioned results, $24 \mathrm{~h}$ was chosen as the hepatocyte induction time for AOX. Compared with the control group, treatment of the rat hepatocytes with 5,10 , and $20 \mu \mathrm{M}$ NIM for $24 \mathrm{~h}$ increased the 7-OH MTX yields by $1.3-, 1.8-$, and 3.1 -fold, respectively (Fig. $3 \mathrm{~b}$ ). In addition, treatment of the human hepatocytes with 10,50 , and $100 \mu \mathrm{M} \mathrm{NIM}$ for $24 \mathrm{~h}$ increased the 7-OH MTX yields by 1.3-, 1.7-, and 2.0-fold, respectively (Fig. 3c).

NIM underwent extensive metabolism in humans and rats. The role of the metabolites in modulating AOX activity was also evaluated. As displayed in Fig. 3b, treatment of rat hepatocytes with $20 \mu \mathrm{M} \mathrm{M1}, \mathrm{M} 2$ or M4 for $24 \mathrm{~h}$ did not increase $7-\mathrm{OH}$ MTX formation. Treatment of human hepatocytes with $20 \mu \mathrm{M}$ M2 or M4 did not increase 7-OH MTX formation (Fig. 3c). However, the treatment of human hepatocytes with $20 \mu \mathrm{M} \mathrm{M} 1$ increased 7-OH MTX formation by 1.4 -fold.

Effects of NIM on AOX protein and mRNA levels in rat and human hepatocytes

The effects of NIM on AOX protein and mRNA levels were investigated to explore the mechanism in the regulation of $\mathrm{AOX}$ activity. Two isoforms, $\mathrm{AOX} 1$ and $\mathrm{AOX} 3$, have been reported for rat AOX [26]. In rat hepatocytes, NIM increased the AOX1 protein level but decreased the AOX3 protein level in a
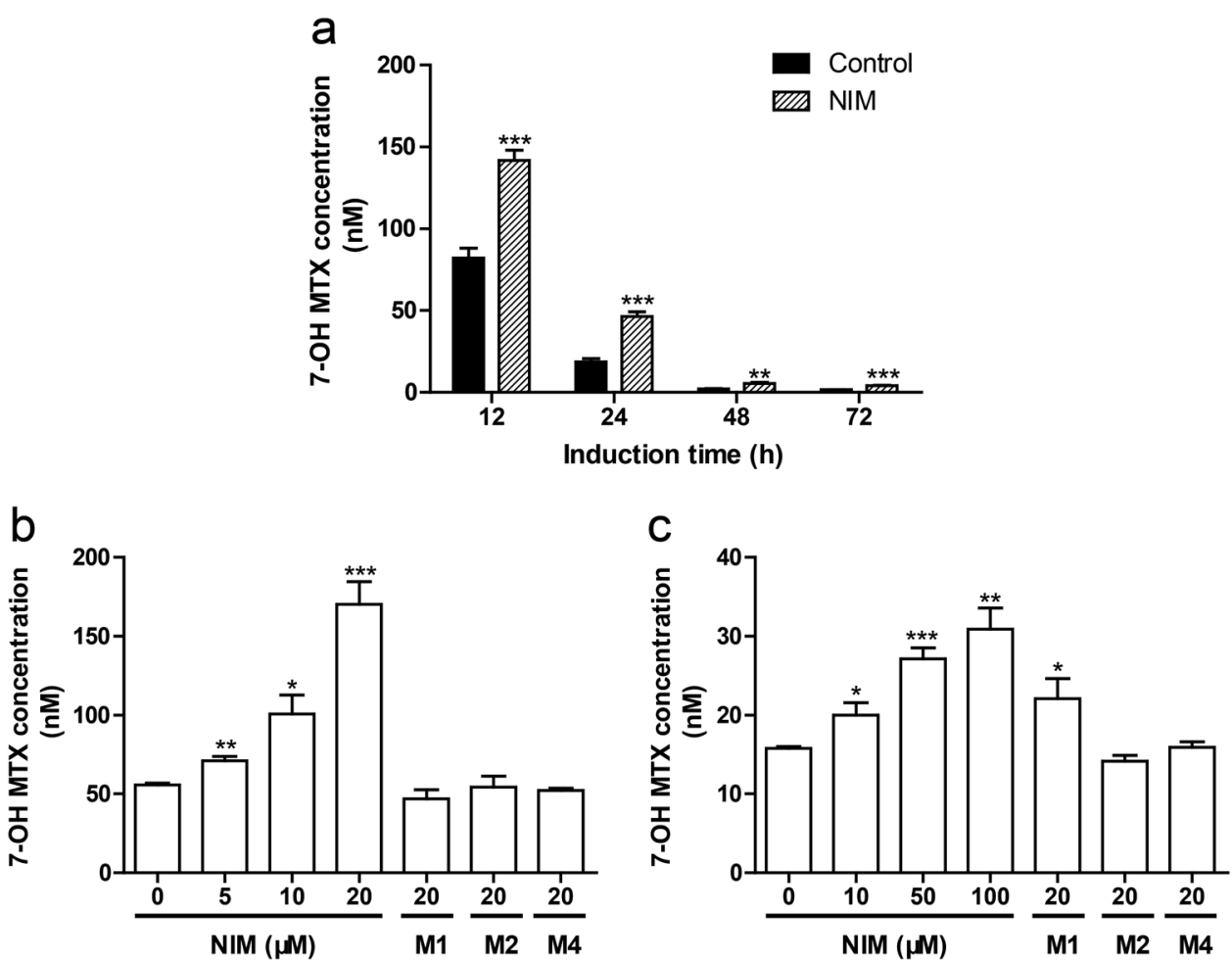

Fig. 3 Effects of NIM and its metabolites on AOX activity in rat and human hepatocytes. a Effect of induction time on the induction response of AOX activity. The rat hepatocytes were treated with either $0.1 \%$ DMSO (control) or $20 \mu \mathrm{M} \mathrm{NIM} \mathrm{for} 12,24,48$, or $72 \mathrm{~h}$. At the end of the induction period, the AOX activity was determined using the substrate MTX $(50 \mu \mathrm{M})$. Effects of NIM and its main metabolites on AOX activity in rat (b) and human (c) hepatocytes. Hepatocytes were treated with various concentrations of NIM (0-20 $\mu \mathrm{M}$ NIM for rat hepatocytes and $0-100 \mu \mathrm{M}$ NIM for human hepatocytes) and its main metabolites ( $20 \mu \mathrm{M} \mathrm{M1}, \mathrm{M} 2$ or M4) for $24 \mathrm{~h}$. At the end of the induction period, the hepatocytes were treated with MTX $(50 \mu \mathrm{M})$ to determine the AOX activity. Data are representative of three independent experiments and are reported as mean \pm SD. ${ }^{*} P<0.05$, ${ }^{* *} P<0.01$, and ${ }^{* * *} P<0.001$ vs. the control group. 
a

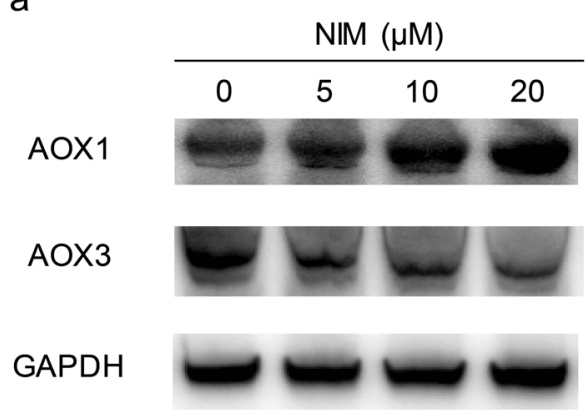

C

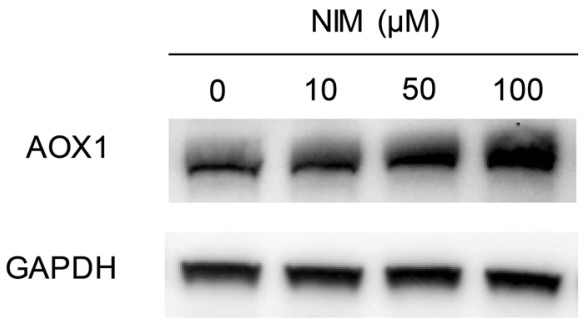

b

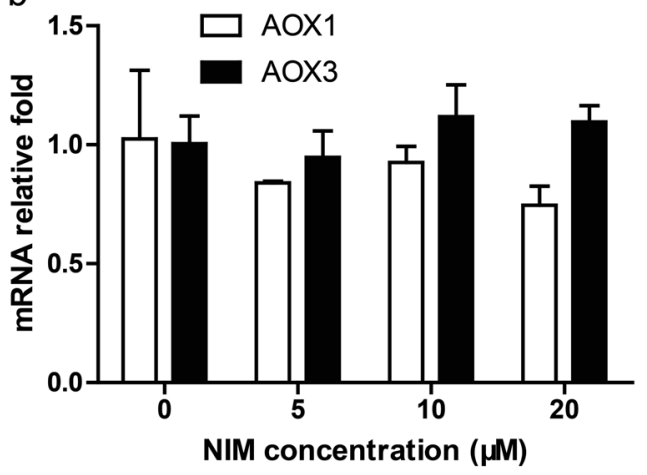

d

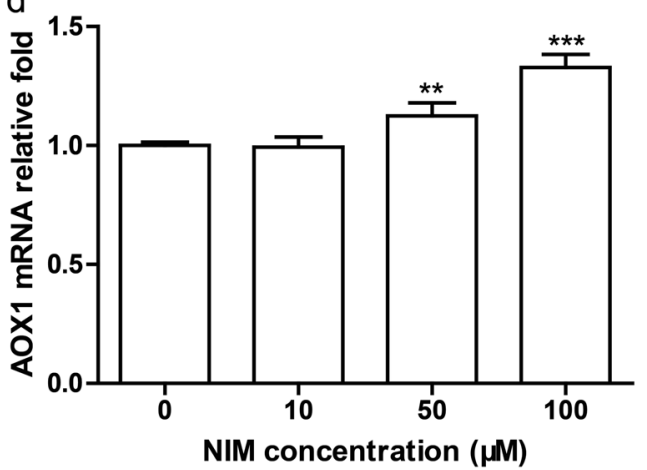

Fig. 4 Effects of NIM on AOX protein and mRNA levels in rat and human hepatocytes. Effects of NIM on the protein (a) and mRNA (b) levels of AOX1 and AOX3 in rat hepatocytes. Effects of NIM on the protein (c) and mRNA (d) levels of AOX1 in human hepatocytes. The hepatocytes were incubated with various concentrations of NIM (0-20 $\mu \mathrm{M}$ for rat hepatocytes and $0-100 \mu \mathrm{M}$ for human hepatocytes) for $24 \mathrm{~h}$. At the end of incubation, the hepatocytes were collected and processed as described in the Materials and methods. For Western blot data, each lane represents extracts from a pool of triplicate incubations $(\mathbf{a}, \mathbf{c})$. Gene expression data $(\mathbf{b}, \mathbf{d})$ were normalized against the endogenous control GAPDH (rat) and PPIA (human). The data are compiled from three independent experiments and are reported as mean \pm SD. ${ }^{* *} P<0.01$ and $* * * P<0.001$ vs. the control group.

concentration-dependent manner (Fig. 4a). NIM did not alter the mRNA levels of AOX1 and AOX3 (Fig. 4b).

Human liver expresses only AOX1 [26]. NIM increased the AOX1 protein level in human hepatocytes in a concentration-dependent manner (Fig. 4c). Moreover, a slight increase ( $<1.5$-fold) in AOX1 mRNA levels was observed (Fig. 4d).

Effects of NIM on the disposition of MTX and 7-OH MTX in rats The effects of NIM on the pharmacokinetics of MTX and 7-OH MTX in rats were investigated. The plasma concentration-time curves of MTX and its main metabolite 7-OH MTX are shown in Fig. $5 a$, b. Table 2 lists the related pharmacokinetic parameters. Compared with the control group, oral administration of $100 \mathrm{mg} \cdot \mathrm{kg}^{-1} \cdot \mathrm{d}^{-1}$ NIM to Wistar rats for 5 days increased the $C_{\max }$ and $A \cup C_{0-24}$ of MTX by 1.7- and 2.0-fold, respectively, and increased the $C_{\max }$ and $\mathrm{AUC}_{0-24}$ of 7-OH MTX by 4.3- and 6.5-fold, respectively.

The effects of NIM on the liver distribution of MTX and 7-OH MTX in rats were also evaluated. The MTX concentration in the livers of NIM-treated rats decreased by $34 \%$ at $4 \mathrm{~h}$ after MTX administration, whereas that of $7-\mathrm{OH}$ MTX increased by 2.5 -fold (Fig. 5c).

Finally, the effects of NIM on the urinary and fecal excretion of MTX and 7-OH MTX were assessed. The accumulated excretion of MTX in $0-24 \mathrm{~h}$ urine increased by 1.8 -fold, and no significant change was observed in the accumulated excretion of MTX in $0-24 \mathrm{~h}$ feces (Fig. $5 \mathrm{~d}$ ). In addition, the accumulated excretion of 7OH MTX in 0-24 h urine and feces increased by 5.2- and 2.1-fold, respectively (Fig. $5 \mathrm{e}$ ).
Dose- and time-dependent increase in AOX activity in rats treated with NIM

Rats were orally administered 20,50 , or $100 \mathrm{mg} \cdot \mathrm{kg}^{-1} \cdot \mathrm{d}^{-1} \mathrm{NIM}$ or vehicle for 5 days or administered $100 \mathrm{mg} \cdot \mathrm{kg}^{-1} \cdot \mathrm{d}^{-1}$ NIM or vehicle for 1,3 , or 5 days. The livers were collected at the indicated times. The AOX activity in rat livers was evaluated by measuring the AOXmediated metabolites from probe substrates (MTX, SGX523, JNJ38877605, and phthalazine) in liver cytosols prepared from different groups of rats.

The 7-OH MTX formation in the liver cytosol from rats pretreated with 20,50 , and $100 \mathrm{mg} \cdot \mathrm{kg}^{-1} \cdot \mathrm{d}^{-1}$ NIM for 5 days increased by 1.9-, 3.2-, and 3.7-fold, respectively, compared with that from rats pretreated with the vehicle (Fig. 6a). In addition, the 7-OH MTX formation in the liver cytosol from rats pretreated with $100 \mathrm{mg} \cdot \mathrm{kg}^{-1} \cdot \mathrm{d}^{-1}$ NIM for 1,3 , and 5 days increased by 1.0-, 2.0-, and 3.8-fold, respectively (Fig. 6b). The addition of menadione, a specific AOX inhibitor [4], markedly suppressed 7-OH MTX formation. Moreover, the AOX-mediated metabolites from SGX523, JNJ-38877605, and phthalazine in the liver cytosol from NIM-treated rats $\left(100 \mathrm{mg} \cdot \mathrm{kg}^{-1} \cdot \mathrm{d}^{-1}\right.$ dose, 5 days) increased by 3.4-, 3.8-, and 2.5-fold, respectively, compared with those from nontreated rats (Fig. $6 \mathrm{c}$ ).

Effects of NIM on AOX protein and mRNA levels in rat livers NIM increased the AOX1 protein level but decreased the AOX3 protein level in a dose-dependent manner (Fig. 7a). Moreover, no significant alteration in the mRNA levels of AOX1 and AOX3 was observed (Fig. 7b). 
a

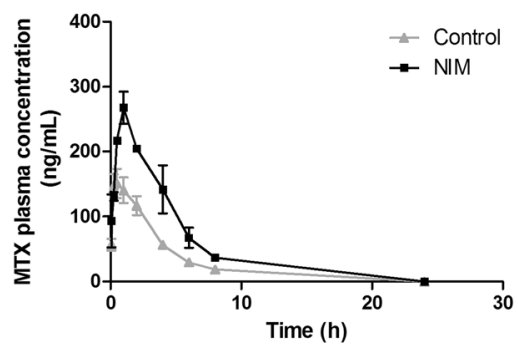

d

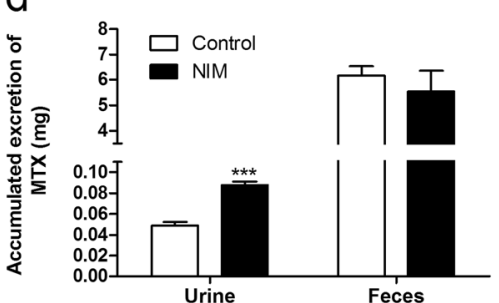

$\mathrm{b}$ 点
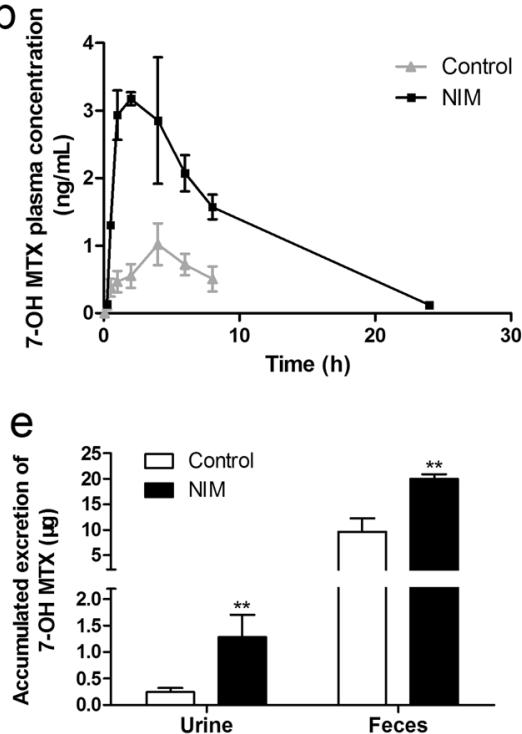

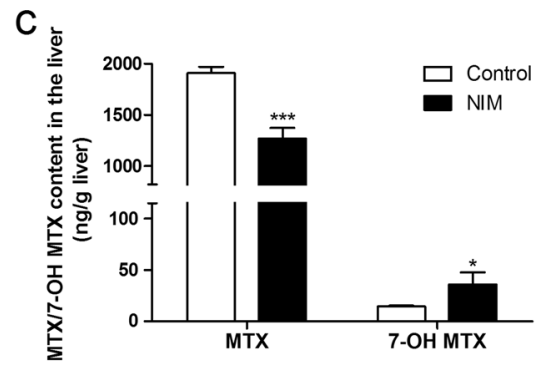

Fig. 5 Effects of NIM on the disposition of MTX and 7-OH MTX in rats. Plasma concentration-time profiles of MTX (a) and 7-OH MTX (b). Liver contents of MTX and 7-OH MTX at $4 \mathrm{~h}$ after oral administration of MTX (c). Accumulated excretion of MTX (d) and 7-OH MTX (e) in 0-24 $\mathrm{h}$ urine and feces. Rats were pretreated with $100 \mathrm{mg} \cdot \mathrm{kg}^{-1} \cdot \mathrm{d}^{-1} \mathrm{NIM}$ or $0.5 \%$ CMC-Na by gavage for 5 days. At $24 \mathrm{~h}$ after the last dose, all rats were orally administered with $50 \mathrm{mg} / \mathrm{kg}$ MTX. Data are reported as mean $\pm \mathrm{SD}(n=4)$. ${ }^{*} P<0.05,{ }^{* *} P<0.01$, and ${ }^{* * *} P<0.001$ vs. the control group.

Table 2. Pharmacokinetic parameters of MTX and 7-OH MTX after oral administration of MTX $(50 \mathrm{mg} / \mathrm{kg})$ to rats pretreated with $100 \mathrm{mg} \cdot \mathrm{kg}^{-1} \cdot \mathrm{d}^{-1}$ NIM or $0.5 \%$ CMC-Na by gavage for 5 days.

\begin{tabular}{|c|c|c|c|c|}
\hline & \multicolumn{2}{|l|}{ MTX } & \multicolumn{2}{|l|}{ 7-OH MTX } \\
\hline$t_{1 / 2}(\mathrm{~h})$ & $2.45 \pm 0.692$ & $2.39 \pm 0.597$ & $5.19 \pm 1.64$ & $4.47 \pm 1.66$ \\
\hline$t_{\max }(\mathrm{h})$ & $0.563 \pm 0.315$ & $0.833 \pm 0.289$ & $3.50 \pm 1.91$ & $3.00 \pm 1.00$ \\
\hline $\mathrm{MRT}_{0-24}(\mathrm{~h})$ & $3.43 \pm 0.573$ & $4.01 \pm 0.195$ & $4.33 \pm 0.100$ & $6.16 \pm 0.550^{* * *}$ \\
\hline$C_{\max }(\mu \mathrm{g} / \mathrm{L})$ & $161 \pm 36.8$ & $268 \pm 42.5^{* *}$ & $0.870 \pm 0.440$ & $3.75 \pm 0.740^{* * *}$ \\
\hline
\end{tabular}

\section{DISCUSSION}

The number of drugs metabolized by AOX is increasing. However, AOX-mediated drug interactions are seldom reported due to the lack of appropriate inhibitors and inducers. To date, no published studies have focused on AOX induction by commonly used clinical drugs. This study demonstrated for the first time that NIM, a commonly prescribed nonsteroidal anti-inflammatory drug, could increase the AOX activity of humans and rats.

To our knowledge, CYP induction studies are usually conducted following $48-72 \mathrm{~h}$ of treatment of hepatocytes with a test inducer to achieve the maximal induction response. However, few studies have focused on the optimal induction time for AOX activity. Thus, the effect of induction time on the induction response of AOX was first investigated in our study. MTX was mainly metabolized to 7OH MTX by AOX [1-3] and was used as a probe substrate to evaluate the AOX activity. The AOX activity in rat hepatocytes decreased with the increase in the preincubation period, and no significant difference was observed in the induction response of $24 \mathrm{~h}$ compared with that of 48 or $72 \mathrm{~h}$. Thus, $24 \mathrm{~h}$ was chosen as the hepatocyte induction time for AOX activity.

Based on our previous studies, NIM was toxic to rat and human hepatocytes, with $\mathrm{IC}_{50}$ values of 40 and $213 \mu \mathrm{M}$, respectively [20]. To avoid a toxic response, the NIM concentration ranges of $0-20$ and $0-100 \mu \mathrm{M}$ were selected for the induction of AOX in rat and human hepatocytes, respectively. Treatment of rat and human hepatocytes with NIM for $24 \mathrm{~h}$ increased the 7-OH MTX formation in a concentration-dependent manner, indicating that NIM could increase the AOX activity of humans and rats. The turnover of MTX to 7-OH MTX mediated by AOX was low in human and rat hepatocytes, indicating that human and rat AOX had a very low affinity for MTX. Similar results were also reported in previous studies $[1,3]$. 7-OH MTX was not detected in patients receiving conventional-dose therapy. However, with high dose $(>50 \mathrm{mg}$ $\mathrm{MTX} / \mathrm{kg}$ ) therapy regimens employed for the treatment of certain cancers, as high as $33 \%$ of MTX could be excreted as 7-OH MTX [21]. These data suggested that the conversion of MTX to 7-OH MTX was a dose-dependent phenomenon with the enzyme involved having a low affinity.

Treatment of the rat hepatocytes with the NIM metabolites did not increase the 7-OH MTX formation, suggesting that the increase in rat AOX activity was due to NIM itself instead of its metabolites. Interestingly, treatment of human hepatocytes with $20 \mu \mathrm{M} \mathrm{M} 1$ for $24 \mathrm{~h}$ increased 7-OH MTX formation by 1.4 -fold, indicating that M1 could increase human AOX activity. The different effects of $M 1$ on human and rat AOX activity suggested that species differences existed in AOX induction. 

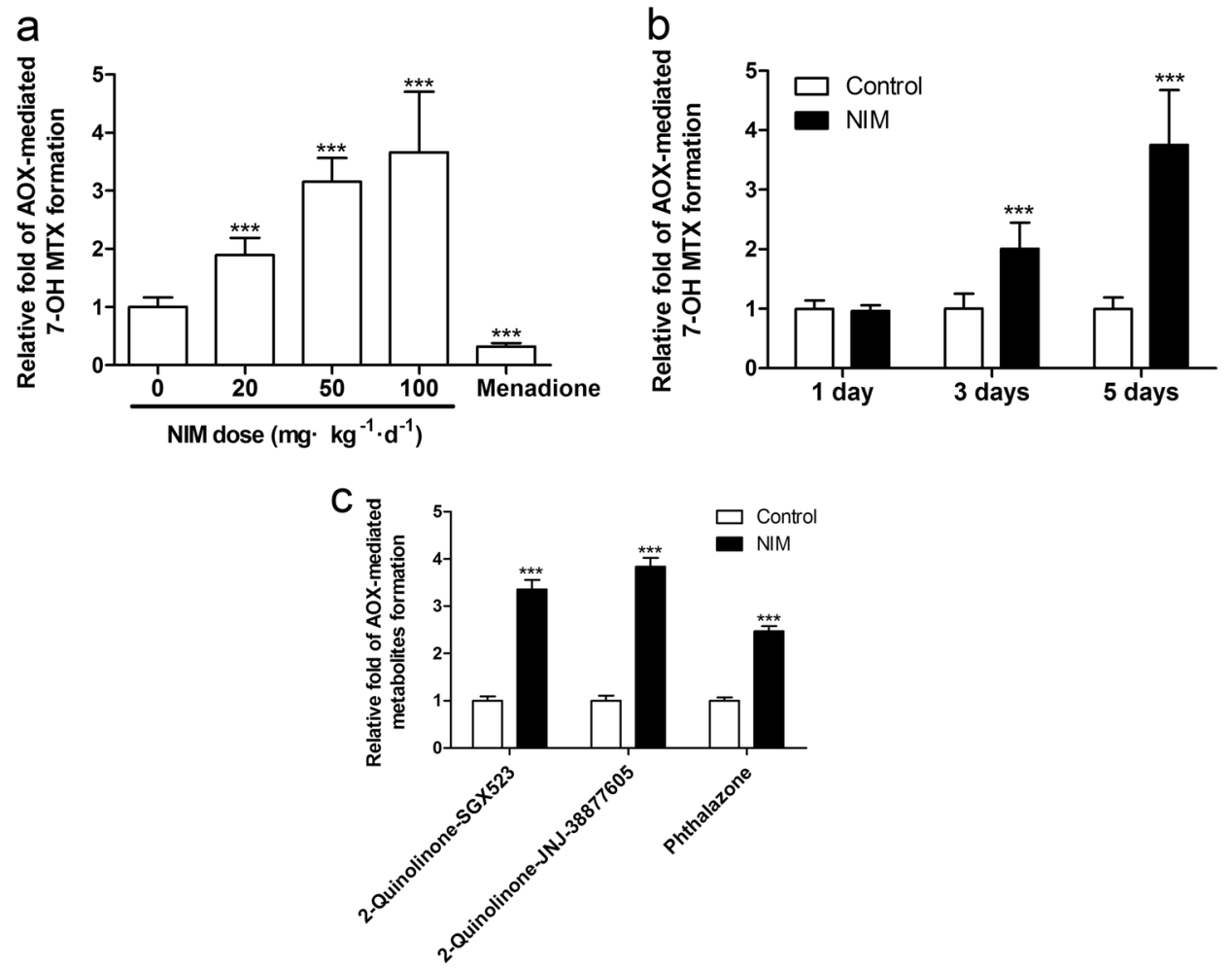

Fig. 6 Dose- and time-dependent increase in AOX activity in rats treated with NIM. a AOX-mediated 7-OH MTX formation from MTX in RLC from rats pretreated with 20,50 , and $100 \mathrm{mg} \cdot \mathrm{kg}^{-1} \cdot \mathrm{d}^{-1} \mathrm{NIM}$ or $0.5 \%$ CMC-Na as a control for 5 days. Menadione was used as a specific AOX inhibitor. b AOX-mediated 7-OH MTX formation from MTX in RLC from rats pretreated with $100 \mathrm{mg}^{\circ} \mathrm{kg}^{-1} \cdot \mathrm{d}^{-1} \mathrm{NIM}$ or the vehicle for 1,3 , and 5 days. c AOX-mediated formation of 2-quinolinone-SGX523, 2-quinolinone-JNJ-38877605, and phthalazone from SGX523, JNJ-38877605, and phthalazine, respectively, in RLC from rats pretreated with $100 \mathrm{mg} \cdot \mathrm{kg}^{-1} \cdot \mathrm{d}^{-1} \mathrm{NIM}$ or the vehicle for 5 days. Data are reported as mean \pm SD $(n=$ 5). ${ }^{* *} P<0.001$ vs. the control group.

Furthermore, in vivo experiments were carried out to verify the in vitro results. Oral administration of $100 \mathrm{mg} \cdot \mathrm{kg}^{-1} \cdot \mathrm{d}^{-1}$ NIM to rats for 5 days significantly increased the systematic exposure (6.5fold), liver distribution (2.5-fold), and the urinary (5.2-fold) and fecal (2.1-fold) excretion of $7-\mathrm{OH}$ MTX, indicating that NIM significantly increased the 7-OH MTX formation in rats.

The effect of NIM on AOX activity in rat livers was evaluated. Rats were administered NIM with different doses and times. The AOX activity in rat livers was characterized by the formation of 7OH MTX in liver cytosols prepared from different groups of rats. A dose- and time-dependent increase in AOX activity was confirmed in the livers of rats in response to NIM. In addition to MTX, the metabolism of other AOX substrates was also enhanced. All these findings demonstrated that NIM pretreatment increased AOX activity in rat livers.

Previous studies demonstrated that NIM underwent nitroreduction by AOX [20, 27]. According to Paragas et al. [28], reductive transformation occurred at a second site within AOX that was kinetically distinct from the oxidative site. The nitro-reduction of NIM might be involved in AOX enzyme stabilization, thus increasing its activity. To test this hypothesis, various concentrations of NIM $(5-20 \mu \mathrm{M})$ were directly added to the RLC incubation of MTX. However, compared with the incubation containing no NIM, no significant difference in 7-OH MTX formation was observed (Supplementary Fig. S1), indicating that the increase in AOX activity by NIM was not due to direct activation.

The protein and mRNA levels were analyzed to consider the mechanism involved. NIM increased the AOX1 protein level but decreased the AOX3 protein level in rat livers. Vila et al. [29] reported that $A O X 1$ and $A O X 3$ oxidized the same spectrum of exogenous substrates, and AOX 1 was more efficient than $A O X 3$ in oxidizing various substrates. This might explain why the elevation of AOX activity in the liver of NIM-treated rats was observed, although the AOX3 protein level decreased. Consistent with the results obtained from rat experiments, a concentration-dependent increase in the AOX1 protein level was observed in human hepatocytes treated with NIM. Notably, there was no significant alteration of AOX mRNA levels after NIM treatment. The inconsistency between the mRNA level of AOX and the corresponding protein level and activity has been reported by a few studies [13, 30-32]. The studies by Calzi et al. showed that a correlation between AOX mRNA and protein levels in various tissues was not always evident, suggesting that both transcriptional and translational events controlled the expression of AOX [30]. Kurosaki et al. reported that despite similar amounts of AOX1 mRNA in the livers of male and female mice, the corresponding protein level and enzyme activity in the livers of male mice were significantly higher than those in female mice. It was likely that androgens regulated AOX activity by a translational or posttranslational mechanism [31]. Rivera et al. documented that there was a remarkable time lag between the accumulation of AOX1 mRNA and its translational products during the induction of AOX1 by dioxin, indicating that factors other than increased gene transcription contributed to the regulation of AOX1 [13]. All these reports showed that the mechanisms by which NIM increased AOX activity were highly complicated and should be investigated from a variety of aspects, which would be the subjects of future studies.

The $C_{\max }$ and AUC values of MTX also increased in the plasma of NIM-treated rats, which was not consistent with the results of only increasing the AOX activity due to NIM. It has been reported that MTX is a substrate of the uptake transporter organic anion transporting polypeptides (OATPs) and efflux transporters breast cancer resistance protein (BCRP) and multidrug resistance- 
a

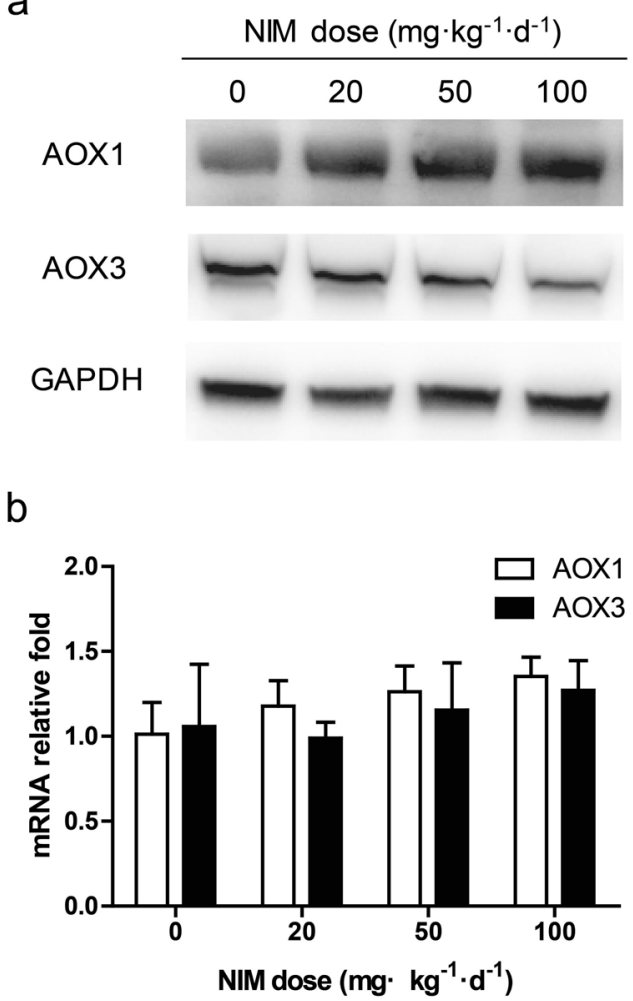

Fig. 7 Effects of NIM on AOX protein and mRNA levels in rat livers. a Effects of NIM on the protein levels of AOX 1 and AOX 3 in rat livers. b Effects of NIM on the mRNA levels of AOX1 and AOX3 in rat livers. The rats were orally administered with 20,50, and $100 \mathrm{mg} \cdot \mathrm{kg}^{-1} \cdot \mathrm{d}^{-1}$ NIM or $0.5 \%$ CMC-Na as a control for 5 days. The rats were then sacrificed, and liver samples were collected and processed as described in the Materials and methods. For Western blot data, each lane represents extracts from a pool of five animals. Gene expression data are reported as mean \pm SD $(n=5)$.

associated protein 2 (MRP2) [33-35]. Our previous studies also demonstrated that NIM was an inhibitor of OATPs and MRP2 [19]. Thus, the transporter-based drug interactions between NIM and MTX might affect the distribution and metabolism of MTX in rats. Herein, a sandwich-cultured rat hepatocyte experiment [19] was performed to evaluate the effect of NIM on the hepatobiliary disposition of MTX. NIM reduced the cellular plus biliary accumulation of MTX in a concentration-dependent manner. Moreover, the biliary excretion index (BEI) of MTX was not changed after NIM treatment (Supplementary Fig. S2). These results showed that NIM significantly inhibited the uptake of MTX and did not inhibit the efflux of MTX, which led to decreased liver exposure and increased plasma exposure of MTX in rats. Although MTX exposure in NIM-treated rat liver was reduced, the concentration of the metabolite 7-OH-MTX was still increased due to the increased AOX activity caused by NIM.

In conclusion, this study demonstrated for the first time that NIM could increase the AOX activity of humans and rats. Our results may partially explain the increased liver injury risk of MTX caused by the combination with NIM and may raise concerns regarding the risk of drug interactions between NIM and AOX substrates in clinical practice.

\section{ACKNOWLEDGEMENTS}

This work was supported by the National Natural Science Foundation of China (Grants 81573500 and 81573351) and the Strategic Priority Research Program of the Chinese Academy of Sciences (XDA 12050306). We thank Dr. Jing-fang Jiang and Dr. Ye Xu for assistance with the rat studies.

\section{AUTHOR CONTRIBUTIONS}

$L Z, X Y P$, and $X Y C$ were responsible for the research design and data analysis. $L Z, X Y P$, $X Y H, L L$, and ZTG conducted the study. LZ and XYC contributed to the writing of the paper.

\section{ADDITIONAL INFORMATION}

The online version of this article (https://doi.org/10.1038/s41401-019-0336-3) contains supplementary material, which is available to authorized users.

Competing interests: The authors declare no competing interests.

\section{REFERENCES}

1. Jordan CGM, Rashidi MR, Laljee H, Clarke SE, Brown JE, Beedham C. Aldehyde oxidase-catalysed oxidation of methotrexate in the liver of guinea-pig, rabbit and man. J Pharm Pharmacol. 1999;51:411-8.

2. Behera D, Pattem R, Gudi G. Effect of commonly used organic solvents on aldehyde oxidase-mediated vanillin, phthalazine and methotrexate oxidation in human, rat and mouse liver subcellular fractions. Xenobiotica. 2014;44:722-33.

3. Choughule KV, Joswig-Jones CA, Jones JP. Interspecies differences in the metabolism of methotrexate: an insight into the active site differences between human and rabbit aldehyde oxidase. Biochem Pharmacol. 2015;96:288-95.

4. Diamond S, Boer J, Maduskuie TP Jr, Falahatpisheh N, Li Y, Yeleswaram S. Speciesspecific metabolism of SGX523 by aldehyde oxidase and the toxicological implications. Drug Metab Dispos. 2010;38:1277-85.

5. Lolkema MP, Bohets $\mathrm{HH}$, Arkenau HT, Lampo A, Barale E, de Jonge MJ, et al. The c-Met tyrosine kinase inhibitor JNJ-38877605 causes renal toxicity through species-specific insoluble metabolite formation. Clin Cancer Res. 2015;21: 2297-304.

6. Nirogi R, Kandikere V, Palacharla RC, Bhyrapuneni G, Kanamarlapudi VB, Ponnamaneni RK, et al. Identification of a suitable and selective inhibitor towards aldehyde oxidase catalyzed reactions. Xenobiotica. 2014;44:197-204.

7. Obach RS, Huynh P, Allen MC, Beedham C. Human liver aldehyde oxidase: inhibition by 239 drugs. J Clin Pharmacol. 2004;44:7-19.

8. Obach RS. Potent inhibition of human liver aldehyde oxidase by raloxifene. Drug Metab Dispos. 2004;32:89-97.

9. Pryde DC, Dalvie D, Hu Q, Jones P, Obach RS, Tran TD. Aldehyde oxidase: an enzyme of emerging importance in drug discovery. J Med Chem. 2010;53:8441-60.

10. Johnson C, Stubley-Beedham C, Stell JGP. Elevation of molybdenum hydroxylase levels in rabbit liver after ingestion of phthalazine or its hydroxylated metabolite. Biochem Pharmacol. 1984;33:3699-705.

11. Ohkubo M, Sakiyama S, Fujimura S. Increase of nicotinamide methyltransferase and N1-methyl-nicotinamide oxidase activities in the livers of the rats administered alkylating agents. Cancer Lett. 1983;21:175-81.

12. Sugihara K, Kitamura S, Yamada T, Ohta S, Yamashita K, Yasuda M, et al. Aryl hydrocarbon receptor (AhR)-mediated induction of xanthine oxidase/xanthine dehydrogenase activity by 2,3,7,8-tetrachlorodibenzo-p-dioxin. Biochem Biophys Res Commun. 2001;281:1093-9.

13. Rivera SP, Choi HH, Chapman B, Whitekus MJ, Terao M, Garattini E, et al. Identification of aldehyde oxidase 1 and aldehyde oxidase homologue 1 as dioxininducible genes. Toxicology. 2005;207:401-9.

14. Al-Abd AM, Inglis JJ, Nofal $S M$, Khalifa $A E$, Williams RO, El-Eraky Wl, et al. Nimesulide improves the disease modifying anti-rheumatic profile of methotrexate in mice with collagen-induced arthritis. Eur J Pharmacol. 2010;644: 245-50.

15. Langerová $P$, Prokeš $M$, Konvalinka $M$, Fürstová J, Urbánek K. Incidence of potential drug interactions in medication prescriptions for children and adolescents in the University Hospital Olomouc, Czech Republic. Eur J Pediatr. 2013;172:631-8.

16. Smeland E, Bremnes RM, Andersen A, Jaeger R, Eide TJ, Huseby NE, et al. Renal and hepatic toxicity after high-dose 7-hydroxymethotrexate in the rat. Cancer Chemother Pharmacol. 1994;34:119-24.

17. Smeland E, Fuskevåg OM, Nymann K, Svendsen JS, Olsen R, Lindal S, et al. Highdose 7-hydroxymethotrexate: acute toxicity and lethality in a rat model. Cancer Chemother Pharmacol. 1996;37:415-22.

18. Fuskevåg $\mathrm{O}-\mathrm{M}$, Kristiansen $\mathrm{C}$, Lindal $\mathrm{S}$, Aarbakke J. Maximum tolerated doses of methotrexate and 7-hydroxy-methotrexate in a model of acute toxicity in rats. Cancer Chemother Pharmacol. 2000;46:69-73.

19. Zhou L, Pang X, Jiang J, Zhong D, Chen X. Nimesulide and 4 '-hydroxynimesulide as bile acid transporters inhibitors are contributory factors for drug-induced cholestasis. Drug Metab Dispos. 2017;45:441-8. 
20. Zhou L, Pang X, Xie C, Zhong D, Chen X. Chemical and enzymatic transformations of nimesulide to GSH conjugates through reductive and oxidative mechanisms. Chem Res Toxicol. 2015;28:2267-77.

21. Jacobs SA, Stoller RG, Chabner BA, Johns DG. 7-Hydroxymethotrexate as a urinary metabolite in human subjects and rhesus monkeys receiving high dose methotrexate. J Clin Invest. 1976;57:534-8.

22. Lankelma J, van der Klein E, Ramaekers F. The role of 7-hydroxymethotrexate during methotrexate anti-cancer therapy. Cancer Lett. 1980;9:133-42.

23. Stiborova $M$, Dracinska $H$, Hajkova J, Kaderabkova $P$, Frei E, Schmeiser $H H$, et al The environmental pollutant and carcinogen 3-nitrobenzanthrone and its human metabolite 3-aminobenzanthrone are potent inducers of rat hepatic cytochromes P450 $1 \mathrm{~A} 1$ and $-1 \mathrm{~A} 2$ and $\mathrm{NAD}(\mathrm{P}) \mathrm{H}$ :quinone oxidoreductase. Drug Metab Dispos. 2006;34:1398-405.

24. Xu Y, Li L, Wang Y, Xing J, Zhou L, Zhong D, et al. Aldehyde oxidase mediated metabolism in drug-like molecules: a combined computational and experimental study. J Med Chem. 2017;60:2973-82.

25. Chladek J, Martinkova J, Sispera L. An in vitro study on methotrexate hydroxylation in rat and human liver. Physiol Res. 1997;46:371-9.

26. Garattini E, Fratelli $M$, Terao $M$. The mammalian aldehyde oxidase gene family. Hum Genomics. 2009;4:119-30.

27. Ogiso T, Fukami T, Mishiro K, Konishi K, Jones JP, Nakajima M. Substrate selectivity of human aldehyde oxidase 1 in reduction of nitroaromatic drugs. Arch Biochem Biophys. 2018;659:85-92.

28. Paragas EM, Humphreys SC, Min J, Joswig-Jones CA, Jones JP. The two faces of aldehyde oxidase: oxidative and reductive transformations of 5-nitroquinoline. Biochem Pharmacol. 2017;145:210-7.
29. Vila R, Kurosaki M, Barzago MM, Kolek M, Bastone A, Colombo L, et al. Regulation and biochemistry of mouse molybdo-flavoenzymes. The DBA/2 mouse is selectively deficient in the expression of aldehyde oxidase homologues 1 and 2 and represents a unique source for the purification and characterization of aldehyde oxidase. J Biol Chem. 2004;279:8668-83.

30. Calzi ML, Raviolo C, Ghibaudi E, de Gioia L, Salmona M, Cazzaniga G, et al. Purification, CDNA cloning, and tissue distribution of bovine liver aldehyde oxidase. J Biol Chem. 1995;270:31037-45.

31. Kurosaki M, Demontis S, Barzago MM, Garattini E, Terao M. Molecular cloning of the CDNA coding for mouse aldehyde oxidase: tissue distribution and regulation in vivo by testosterone. Biochem J. 1999;341(Pt 1):71-80.

32. Itoh K, Adachi M, Sato J, Shouji K, Fukiya K, Fujii K, et al. Effects of selenium deficiency on aldehyde oxidase 1 in rats. Biol Pharm Bull. 2009;32:190-4.

33. van de Steeg $E$, van Esch A, Wagenaar E, Kenworthy KE, Schinkel AH. Influence of human OATP1B1, OATP1B3, and OATP1A2 on the pharmacokinetics of methotrexate and paclitaxel in humanized transgenic mice. Clin Cancer Res. 2013;19:821-32.

34. van de Steeg E, van der Kruijssen CM, Wagenaar E, Burggraaff JE, Mesman E, Kenworthy $\mathrm{KE}_{\text {, et }}$ al. Methotrexate pharmacokinetics in transgenic mice with liver-specific expression of human organic anion-transporting polypeptide 1B1 (SLCO1B1). Drug Metab Dispos. 2009;37:277-81.

35. Vlaming $M L$, van Esch $A$, van de Steeg $E$, Pala Z, Wagenaar $E$, van Tellingen $O$. et al. Impact of abcc2 [multidrug resistance-associated protein (MRP) 2], abcc3 (MRP3), and abcg2 (breast cancer resistance protein) on the oral pharmacokinetics of methotrexate and its main metabolite 7-hydroxymethotrexate. Drug Metab Dispos. 2011;39:1338-44. 